\title{
Trabalho produtivo e improdutivo na atualidade: particularidade do trabalho docente nas federais
}

\author{
Janaína Lopes do Nascimento Duarte \\ Universidade de Brasília (UnB)
}

Trabalho produtivo e improdutivo na atualidade: particularidade do trabalho docente nas federais Resumo: Como resultado de pesquisa bibliográfica para tese de doutorado, este texto aborda o debate contemporâneo sobre o trabalho produtivo e improdutivo, a partir das formulações marxianas, com o objetivo de estabelecer considerações para compreender o trabalho docente nas Instituições de Ensino Superior Federais. O tema sugere maior aprofundamento sobre o trabalho docente no contexto atual de novas relações entre capital-trabalho e mais-valia. Divide-se em quatro partes: trabalho produtivo e improdutivo, a partir das formulações marxianas; a forma social em que o trabalho se realiza, apontando o que é fundamental na análise; o trabalho contemporâneo no magistério superior em termos produtivos/improdutivos para o capital; e, por fim, reflexões sobre a relevância das ações coletivas de resistência como mecanismos que podem vislumbrar novos caminhos para a universidade pública e seu coletivo docente.

Palavras-chave: Trabalho produtivo. Trabalho improdutivo. Educação superior. Trabalho docente.

Productive and unproductive work nowadays: specificities of teaching in federal universities

Abstract: As a result of bibliographic research for a doctoral dissertation, this paper addresses the contemporary debate about productive and unproductive labor, based on Marxian conceptions, with the aim of establishing considerations to understand the work of professors in Higher Education Institutions. The theme suggests greater reflection on the teaching work in the current context of new capital-labor relations and surplus value. It is divided into four parts: productive and unproductive labor, based on Marxian conceptions; the social form in which work is done, indicating what is fundamental in this analysis; contemporary work in higher education in productive/unproductive terms for the capital; and, finally, reflections on the relevance of collective actions of resistance as mechanisms that can envision new paths for public universities and their faculty.

Keywords: Productive labor. Unproductive labor. Higher Education. Teaching.

Recebido em 11.11.2016. Aprovado em 21.02.2017. 


\section{Introdução}

No debate a respeito do trabalho e do seu processo de intensificação e valorização nas diversas áreas na contemporaneidade, em particular na docência do magistério superior nas federais, partimos do pressuposto de que é necessário localizar o trabalho docente no contexto atual de novas relações entre capital-trabalho e mais-valia.

Diante disto, cabe recuperar algumas formulações sobre as categorias trabalho produtivo e improduti$v^{1}{ }^{1}$, em termos marxianos, já que tais categorias se constituem como importantes elementos para a compreensão da dinâmica atual do modo de produção capitalista enquanto processo de produção de mais-valia. Logo, o objetivo do texto é resgatar o debate sobre trabalho produtivo e improdutivo em Marx, a fim de estabelecer algumas considerações sobre o trabalho docente nas Instituições de Ensino Superior (IES) federais localizadas em um contexto que estabelece novas relações entre capital-trabalho e mais-valia na atualidade. Afinal, podemos chamar o trabalho docente atual de produtivo ou improdutivo? Quais as suas relações com a valorização do capital no presente? Tais questionamentos se originam das reflexões contidas, em parte, nos nossos estudos no doutorado em Serviço Social, como resultado de consistente pesquisa bibliográfica sobre o tema.

O texto está dividido em quatro partes: breve retomada das formulações de Marx sobre trabalho produtivo e improdutivo; considerações sobre a forma social em que o trabalho se realiza, apontando o que é fundamental para sua análise; o trabalho no magistério superior em termos produtivos/improdutivos para o capital, tomando como referência o contexto de contrarreforma do ensino superior e a constituição de novas relações de acumulação no presente; para finalizar, reflexões sobre o que é essencial no debate, com destaque para a relevância das ações coletivas de resistência como mecanismos que podem vislumbrar novos caminhos para a universidade pública e seu coletivo docente.

\section{Trabalho produtivo e improdutivo em Marx}

As categorias trabalho ${ }^{2}$ produtivo e improdutivo se caracterizam como importantes elementos para a compreensão da dinâmica do modo de produção capitalista, enquanto processo de produção de mais-valia. Marx (1985c, p. 109) ressalta: "é produtivo aquele trabalho que valoriza diretamente o capital, o que produz mais-valia, ou seja, que se realiza numa mais-valia". Portanto, "trata-se de trabalho que serve diretamente ao capital como instrumento da sua autovalorização, como meio para a produção de mais-valia". Trabalho produtivo é caracterizado como aquele que produz mais-valia e, assim, gera lucro para o capitalista, sendo o trabalhador produtivo não apenas aquele que produz o necessário para a reprodução de sua existência humana, mas, sobretudo, aquele que produz o excedente (um quantum adicional) que alimenta e garante a existência do capitalista. Por conseguinte, o fundamento da produção capitalista consiste no processo de valorização do capital por meio da mais-valia retirada do trabalhador assalariado, considerado produtivo. Santos Neto (2012, p. 8), sintetiza: "É do preço da força de trabalho ${ }^{3}$ que ele retira o seu lucro. Os meios de produção, enquanto trabalho morto, são vivificados pela força de trabalho viva, desse modo ocorre o processo de valorização do capital, ou seja, do valor que se valoriza". No texto sobre "Teorias da mais valia", analisando os estudos de A. Smith, Marx (1980, p. 132, grifos nossos) explica: "Trabalho produtivo no sentido da produção capitalista é o trabalho assalariado que, na troca pela parte variável do capital (a parte do capital despendida em salário - valor da força de trabalho), além de reproduzir essa parte do capital (ou valor da própria força de trabalho), ainda produz mais-valia para o capitalista". Portanto, os trabalhadores produtivos constituem-se como aqueles que produzem "a riqueza imediata, material, consistente em mercadorias, todas as mercadorias, excetuada a constituída pela própria força de trabalho" (MARX, 1980, p. $140)^{4}$. Marx (1985b, p. 106,) retoma o debate de forma mais madura e consistente, articulando organicamente a categoria trabalho produtivo à produção de mais-valia

A produção capitalista não é apenas produção de mercadoria, é essencialmente produção de mais-valia. O trabalhador produz não para si, mas para o capital. Ele tem de produzir mais-valia. Apenas é produtivo o trabalhador que produz mais-valia para o capitalista ou serve à autovalorização do capital. Se for permitido escolher um exemplo fora da esfera da produção material, então um mestre-escola é um trabalhador produtivo se ele não apenas trabalha as cabeças das crianças, mas extenua a si mesmo para enriquecer o empresário. O fato de que este último tenha investido seu capital numa fábrica de ensinar, em vez de numa fábrica de salsichas, não altera nada na relação. O conceito de trabalho produtivo, portanto, não encerra de modo algum apenas uma relação entre a atividade e efeito útil, entre trabalhador e produto do trabalho, mas também uma relação de produção especificamente social, formada historicamente, a qual marca o trabalhador como meio direto de valorização do capital. 
Do exposto, podemos destacar três aspectos importantes sobre o trabalho produtivo: 1) este se constitui como trabalho utilizado no processo direto e imediato de produção, ou seja, trabalho produtor de mais-valia ${ }^{6}$ (gera novos valores), sendo o trabalhador produtivo aquele ligado à esfera da produção, aquele que serve à autovalorização do capital: "é produtivo o trabalhador que executa um trabalho produtivo e é produtivo o trabalho que gera diretamente mais-valia, isto é, que valoriza o capital” (MARX, 1985c, p. 109); 2) não importa a natureza em si da mercadoria, por isso, não necessariamente será produzido um bem material, podendo satisfazer uma necessidade do estômago ou da fantasia; e, como explica Teixeira (1988, p. 7), 3) "encerra, antes de tudo, uma relação social, que se expressa na troca capital/trabalho: o trabalhador produtivo, vendedor de força de trabalho e o capitalista, comprador dessa força de trabalho". Então, "o trabalhador produtivo é um trabalhador assalariado ${ }^{7}$ que produz e valoriza capital, isto é, que produz mais-valia”. Em vista disso, Marx (1980, p. 144) explica:

não é a especialidade do trabalho nem a forma externa de seu produto que necessariamente o tornam 'produtivo' ou 'improdutivo'. O mesmo trabalho poderia tanto ser produtivo, se o compro no papel de capitalista, de produtor, para produzir valor maior, quanto improdutivo, se o compro na função de consumidor, de quem despende renda, para consumir seu valor de uso, não importando que esse valor de uso desapareça com a atividade da própria força de trabalho ou se materialize e fixe numa coisa.

\section{As nuances e a forma social em que o trabalho se realiza: o que é fundamental?}

Marx (1985c, p. 111) analisa que "todo trabalhador produtivo é um assalariado, mas nem todo o assalariado é um trabalhador produtivo”. Para Marx (1980, p. 145), um capitalista pode comprar temporariamente o trabalho improdutivo da força de trabalho de atores, músicos, prostitutas, etc., em que os serviços comprados "perecem no instante do desempenho e não se fixam nem se realizam 'num objeto durável' (também se diz particular) 'ou mercadoria vendável', destacada deles mesmos”. Entretanto, a venda desses serviços ao público lhe possibilita não somente o pagamento da força de trabalho comprada, sob a forma de salário, como também lhe propicia o lucro: "esses serviços capacitam-no a comprá-los de novo, isto é, por meio deles mesmos renova-se o fundo por que são pagos". O mesmo pode acontecer com "o trabalho dos auxiliares que um advogado emprega no escritório" (MARX, 1980, p.146) ou com o trabalho comprado da arrumadeira de quarto por um capitalista, proprietário de um hotel. Como elucida Santos Neto (2012, p. 10), "isso de maneira alguma se contrapõe ao fato de que esses serviços foram pagos com a renda ou derivaram do trabalho produtivo". Então, parte desses serviços pode estar subordinada à lógica capitalista da produção de mais-valia e outra parte pode escapar a tal processo de produção de mais-valia.

Apoiando-se a partir de outro exemplo, Teixeira (1988, p. 8-9) explica que os trabalhadores assalariados que estão fora do processo imediato de produção e, por isso, não produzem mais-valia, como os assalariados do comércio, constituem-se, a partir das análises marxianas, como trabalhadores improdutivos. Porém, estes se situam como "improdutivos interiores à produção capitalista, ao processo de produção e circulação de capital”, pois são funcionais ao modo de produção capitalista e, por isso, inserem-se no processo global de produção. Nestes termos, "tanto o trabalho produtivo como o improdutivo correspondem à relação de trabalho assentadas sobre princípios capitalistas".

Os funcionários públicos, tais como os docentes das federais, encontram-se exteriores ao processo direto de produção de mais-valia, e não vendem sua força de trabalho diretamente ao capital. Entretanto, de acordo com Teixeira (1988, p. 10), “o empregado público está ligado ao Estado, que é uma instituição absolutamente necessária ao sistema (capitalista)". O servidor público "é considerado como trabalhador que, embora exterior à produção, pertence à interioridade do sistema". Seus salários provêm de um fundo constituído por uma redistribuição dos rendimentos do sistema capitalista: "a fonte de seus salários são os impostos, que correspondem a uma parte dos rendimentos (salários, lucros e renda da terra) apropriada pelo Estado". Já os empregados domésticos, também considerados improdutivos, tem sua "força de trabalho comprada com vistas ao seu valor de uso particular: servir às famílias" (TEIXEIRA, 1988, p. 18). Teixeira (1988, p. 18-19) elucida:

Seu trabalho se troca por rendimentos e não por capital. Rendimentos que só podem provir do valor novo, anualmente criado pelo processo de produção. Assim, um empregado doméstico, se contratado por um trabalhador, seus salários serão parte dos salários deste trabalhador; se contratado por um empresário, seus salários serão parte da mais-valia, que se destina ao consumo de seus possuidores; se contratado por um proprietário de terra, terá como salário parte da renda fundiária. 
Então, o funcionário público e o trabalhador doméstico são trabalhadores improdutivos exteriores ao circuito de valorização do valor, mas interiores ao sistema. Por isso, podemos inferir que ser improdutivo não quer dizer dispensável, ou seja, os trabalhadores improdutivos são necessários à reprodução da totalidade do modo de produção capitalista. E o autor explica em outro texto: "Porque é humanamente impossível se pensar o capitalismo sem a presença do Estado e o Estado sem funcionários públicos. O capitalismo só o é porque o Estado é condição de possiblidade de reprodução do próprio capital. Então, o poder de polícia, funcionários ligados à educação, saúde, habitação, etc. são fundamentais para o sistema, mas são improdutivos para o capital" (TEIXEIRA, 1999, p. 5).

O trabalhador autônomo independente também é considerado improdutivo e desenvolve sua atividade "através de prestação de serviços pessoais ou de reparação de utensílios domésticos" (TEIXEIRA, 1988, p. 19), no qual vários consumidores pagam partes do valor integral de sua força de trabalho. Então, "sua força de trabalho é utilizada por seu valor de uso próprio, com vista ao seu consumo pessoal sob a forma de serviços e não com vista a produzir um sobrevalor". Isto porque "se há relação de compra e venda de força de trabalho, esta pode assumir o caráter de uma relação salarial [...] não o sentido de compra e venda da força de trabalho que se troca por capital, mas no sentido geral da compra e venda do trabalho improdutivo (exterior à produção, evidentemente)" (TEIXEIRA, 1988, p. 20).

Desse modo, o trabalhador improdutivo considerado exterior à produção não se constitui como indivíduo externo ao sistema do capital: "Ele está preso ao sistema pela redistribuição dos rendimentos, que se constitui num fundo através dos funcionários do Estado, empregado doméstico, ambulante, autônomos, etc., retiram sua sobrevivência. Em outras palavras, é da redistribuição do valor novo, anualmente criado no processo imediato de produção, que provêm os salários desses trabalhadores" (TEIXEIRA, 1988, p. 21). Sem contar que todos estão imersos na lógica do modo de produção capitalista, uma vez que:

\begin{abstract}
A socialização brutal pelo capital não permite mais a presença de setores da economia produzindo seus próprios meios de produção e mercadorias, artesanalmente. Um produtor independente que produza mercadorias fora dos muros das empresas capitalistas, só o faz porque carrega para sua oficina particular os instrumentos de trabalho produzidos pelas grandes empresas. Até mesmo as matérias-primas por ele utilizadas são produtos do grande capital, de sorte que assim sendo toda a produção é produção do trabalho produtivo (TEIXEIRA, 1988, p. 33).
\end{abstract}

Logo, o que vai qualificar se o trabalho é produtivo ou improdutivo é o lugar onde ele se insere e a relação social que estabelece dentro do processo global de acumulação e reprodução do capital. Por isso, Marx (1980, p. 137) adverte que os conceitos de trabalho produtivo e improdutivo "não decorrem da qualificação material do trabalho (nem da natureza do produto nem da destinação do trabalho como trabalho concreto), mas da forma social determinada, das relações sociais de produção em que ele se realiza". E exemplifica: "Um escritor é trabalhador produtivo não por produzir ideias, mas enquanto enriquece o editor que publica suas obras ou enquanto for o trabalhador assalariado de um capitalista". Logo, "é uma definição do trabalho, a qual não deriva de seu conteúdo ou resultado, mas de sua forma social específica" (MARX, 1980, p. 138):

O trabalhador de um fabricante de piano é um trabalhador produtivo. Seu trabalho, além de substituir o salário que consome, proporciona valor excedente acima do valor do salário no produto, no piano, a mercadoria que o fabricante vende. Se, ao invés disso, compro todo material necessário para fabricar um piano (ou digamos o próprio trabalhador o possua) e, ao invés de comprar o piano na loja, mando fazê-lo em casa, nesse caso, quem faz o piano é trabalhador improdutivo, pois seu trabalho se troca diretamente por minha renda (MARX, 1980, p. 140).

Mais um exemplo esclarecedor é utilizado por Marx (1985c, p. 115):

Uma cantora que canta como um pássaro é uma trabalhadora improdutiva. Na medida em que vende o seu canto é uma assalariada ou uma comerciante. Porém, a mesma cantora contratada por um empresário que a põe a cantar para ganhar dinheiro, é uma trabalhadora produtiva, pois produz diretamente capital. Um mestre-escola que ensina outras pessoas não é um trabalho produtivo. Porém, um mestre-escola que é contratado com outros para valorizar, mediante o seu trabalho, o dinheiro do empresário da instituição que trafica com o conhecimento é um trabalhador produtivo.

Teixeira (1988, p. 16-17) afirma que o desenvolvimento da produção capitalista subordina todo o trabalho às leis deste modo de produção, o que não exclui que "a realidade do capitalismo contemporâneo comporte 
tanto um crescimento dos produtivos, como dos improdutivos exteriores à produção", com tendência de "conversão de todos os indivíduos à interioridade do sistema".

De fato, "os trabalhos produtivo e improdutivo formam um todo estruturado dialeticamente, cujo movimento é determinado pelo processo global de desenvolvimento da acumulação capitalista” (TEIXEIRA, 1988, p. 32). Assim sendo, o fundamental não é qualificar se o trabalho é produtivo ou improdutivo, mas, sobretudo, identificar a relação social estabelecida, ou seja, onde se insere no circuito de produção e reprodução de valor.

Nestes termos, podemos inferir que o essencial neste debate sobre trabalho na condição de produtivo e/ ou improdutivo paira na concepção de que o trabalho se constitui na essência do processo de valorização do capital, porque "nenhuma forma de sociabilidade é possível de existir sem o trabalho" (SANTOS NETO, 2012, p. 19). Por isso, Santos Neto (2012) enfatiza a relevância do debate sobre trabalho produtivo e improdutivo, na medida em que Marx, ao longo da sua obra de compreensão e crítica da anatomia da sociedade capitalista, recupera e avança em relação à economia política clássica quando busca decifrar o código secreto da teoria do valor, da mercadoria e do lucro do capitalista.

A novidade de Marx em relação aos representantes da economia política, como Adam Smith e David Ricardo, está em haver qualificado a natureza do trabalho que produz e agrega valor. No entanto, a economia política padece do problema de tentar naturalizar as relações sociais e o sistema do capital, considerando que as relações de produção que caracterizam a sociedade capitalista como relações eternas e infinitas; ela é incapaz de perceber que o sistema do capital é tão somente uma expressão histórica determinada e que suas categorias econômicas não podem ser encaradas como categorias dominantes nas sociedades precedentes (SANTOS NETO, 2012, p. 19).

Santos Neto (2012, p. 19) ainda ressalta que

o principal defeito da economia política, inclusive de Adam Smith, subsiste ao não compreender as contradições existentes na sociedade capitalista e como elas integram suas diferentes categorias". Isto porque a "economia política acaba por não perceber que a sociedade capitalista pressupõe uma determinada forma de manifestação do trabalho que acaba se distinguindo do trabalho como categoria fundante, mas que jamais poderia emergir desconsiderando-o.

É nisto que Marx supera Adam Smith, pois aponta "o devido lugar que ocupa o trabalho, enquanto mediação da sociedade com a natureza, como categoria fundante do mundo dos homens e de toda forma de sociabilidade" (SANTOS NETO, 2012, p. 19).

\section{0 caso do trabalho docente nas federais}

Em relação ao trabalho do professor do magistério superior na atualidade, em particular no âmbito das universidades federais, temos, como ponto de partida, que localizar o trabalho docente no tempo presente, identificando as determinações e contradições que incidem sobre o mesmo diante do padrão atual de acumulação.

O capitalismo contemporâneo, resultado do último século, apresenta um processo dinâmico e multifacetado que combina altos níveis de exploração do trabalho e extração de mais-valia, em especial a partir da década de 1970, em proporções inimagináveis em relação ao contexto sócio histórico de Marx. A combinação entre reestruturação produtiva, alterações na relação Estado e sociedade, metamorfoses nas condições e relações de trabalho, bem como a predominância do capital financeiro inaugurou uma nova dinâmica, muito mais destrutiva para o trabalho. Silva Jr. e Pimenta (2014, p. 29) afirmam que "a predominância do capital financeiro desconsidera a concreta dinâmica e o real tempo do capital no âmbito das relações sociais de produção e a comprime fazendo com que este ciclo de movimentação do capital sofra redução espaço-temporal no trabalho e na vida". Por isso, os autores defendem que "sob a predominância financeira, a racionalidade que preside o processo de reprodução do capital se constitui como a mesma nas esferas pública e privada" ", uma vez que a lógica de reorganização do capital para expansão global da acumulação acarreta novas determinações sobre as instituições de ensino superior (universidades, especialmente), a produção do conhecimento e o trabalho docente atual.

No Brasil, o investimento estrangeiro direto altera o processo de produção de valor e também aí passa a exigir a diminuição do custo da força de trabalho, aumento de produtividade por meio da pesquisa científica e da diminuição e quase desaparição dos direitos sociais sobre o trabalho. Este processo atinge a esfera 
pública, especialmente as instituições federais de educação superior, por serem parte do aparelho do Estado, ainda que formado por instituições da sociedade civil (SILVA JÚNIOR.; PIMENTA, 2014, p. 29).

É o que induz a universidade a subsidiar diretamente o processo de acumulação na atualidade, por meio da expansão da educação superior sob o domínio da lógica mercantil (haja vista as parcerias público/privado nas universidades federais). Este processo, do ponto de vista da luta de classes, revela a importância estratégica da reflexão sobre a nova natureza do trabalho produtivo no presente (e suas novidades) ${ }^{9}$, considerando aqui três aspectos: a releitura dos escritos de Marx sobre o tema; as novas relações entre capital-trabalho; e a atualidade dos processos que incidem sobre as IES federais e o trabalho docente, cada vez mais intensificado e sobre o domínio do Estado neoliberal e dos setores mercantis.

Retomando a formulação de Marx (1985b, p. 106) que "apenas é produtivo o trabalhador que produz mais-valia para o capitalista ou serve à autovalorização do capital”, Antunes (2013) ressalta que quando utiliza a conjunção alternativa "ou”, Marx nos fornece a chave para analisar as novas formas de extração da maisvalia para além da produção de mercadoria, o que permite ampliar o conceito de trabalho produtivo, de acordo com sua função no processo de valorização do capital.

Aqui localizamos o estratégico papel da educação superior na atualidade: a) com as IES privadas, consideradas grandes conglomerados empresariais altamente rentáveis para o capital em sua fase atual; e b) as IES federais por meio das parcerias público-privado, subsidiando empresas na direção da ampliação de seus lucros, na gestão pautada na lógica empresarial do produtivismo acadêmico, dentre outros aspectos permeados pela racionalidade da produção capitalista ${ }^{10}$ (DUARTE, 2017). Até porque "na ordem capitalista, não há como escapar de sua lógica, sendo a própria organização da educação e da práxis docente, expressão das relações de dominação da sociedade" (BERTOLDO; SANTOS, 2012, p. 109).

As IES federais se inserem no processo de reorganização capitalista, reestruturação e financeirização da economia e da vida, metamorfoseando sua lógica e finalidade para os interesses do capital financeiro, bem como alterando consistentemente o trabalho docente na atualidade, em especial a partir do processo de mercantilização das relações no cotidiano e na mudança da natureza do trabalho e do ser social trabalhador (DUARTE, 2017). Por isso, Silva Jr. e Pimenta (2014, p. 33) afirmam que "a universidade federal tem uma nova institucionalidade que induz ao trabalho produtivo". Como afirma Dal Rosso (2008, p. 34): "Um pesquisador faz uma descoberta científica e o valor desta descoberta pode ser infinito se a descoberta pode ser codificada, mercantilizada, transformada em mercadoria. A faísca cerebral e a fogueira mental que conduziram à descoberta são de natureza distinta do tempo médio e isso lhe confere um potencial infinito de valor". Mancebo (2011, p.35), em breves linhas, expõe o cotidiano intensificado do trabalhador docente:

Os professores de educação superior preparam e ministram cursos na graduação e na pós-graduação, orientam estudantes na graduação e na pós-graduação, organizam eventos, elaboram estratégias de busca de financiamento, fazem gestão das relações entre grupos acadêmicos, estabelecem comunicação entre pares, escolhem 'formas' de produzir e ter sucesso na publicação de um número importante de artigos em revistas conceituadas no seu respectivo campo de atuação, concorrem em editais, buscam parceria na iniciativa privada, preenchem pareceres on line de um número crescente de bolsistas, de revistas, de eventos, de pedidos de financiamento de seus pares e ocupam-se cada vez mais com tarefas administrativas, como alimentação de planilhas, elaboração de relatórios, e por aí vai.

Desta maneira, o trabalho docente segue a tendência predominante no mundo do trabalho sob a égide do padrão de acumulação flexível, uma vez que também vem se flexibilizando, precarizando-se e se intensificando de maneira que as atividades prescritas para o professor são cada vez mais diversificadas, em maior número, em condições diversas e gestadas a partir da lógica empresarial (DUARTE, 2017). Isto porque são tempos em que é cada vez mais necessário que o trabalho renda mais resultados em termos qualitativos e quantitativos. Ou seja, a complexidade do estágio atual do capitalismo e do seu padrão de acumulação exige a busca de fundamentos e a construção de nexos e debates sobre as novas faces da exploração do trabalho que vem rompendo com "o padrão dos tempos de trabalho separado nitidamente dos tempos de não-trabalho" (DAL ROSSO, 2008, p. 35), o que indica que o trabalho é cada vez mais intensamente explorado, mais intensificado, mais valorizado.

\section{Considerações finais}

Diante de polêmicas e contradições, mas considerando as formulações marxianas sobre o tema, a dinâmica atual do capitalismo, seus nexos situados na relação capital trabalho, bem como seus desdobramentos nas 
IES federais e, consequemente, no trabalho docente contemporâneo (graduação e pós-graduação, ainda que com particularidades), compreendemos que independentemente da localização do trabalho no campo produtivo ou improdutivo, nos termos de Marx, ambos estão inseridos na lógica do predomínio do capital financeiro mundializado e, de uma maneira ou de outra, constituem-se como parte integrante e orgânica do processo de valorização do capital. Neste sentido, Silva Jr. e Pimenta (2014, p. 36) destacam que "não pela natureza das ciências, mas pela racionalidade da produção capitalista, a produção científica em grande medida é o móvel de expropriação do saber do trabalhador e sua respectiva apropriação pelo capital", constituindo como "parte do mundo da mercadoria e da criação do valor"; com destaque para a "indústria de serviços em que se transformou a educação superior privada e pública, especialmente no âmbito da pós-graduação".

Os autores divergem entre o fato do trabalho docente se localizar como trabalho improdutivo (SANTOS NETO, 2012), trabalho improdutivo interior à produção (TEIXEIRA, 1988) e como trabalho produtivo ampliado ou não, a partir de novas formas de valorização do capital na atualidade, mas a depender das condições em que este se realiza coletivamente (SILVA JÚNIOR; PIMENTA, 2014; ANTUNES, 2013).

No entanto, neste texto, chamamos a atenção para a necessidade de aprofundamento destas questões a partir de análises sobre o trabalho contemporâneo, sobretudo, a respeito da necessidade do capital de reinventar novas formas de valorização, subordinando toda a dinâmica societária, inclusive a educação superior pública federal e o seu magistério. Assim, "os trabalhos são materiais ou imateriais, produtivos ou improdutivos, mas estão socialmente combinados com o objetivo de valoração do capital em escala global" (SILVA JÚNIOR; PIMENTA, 2014, p. 36). Na verdade, a polarização (inclusive entre professores de IES privadas e públicas) entre trabalhadores produtivos ou improdutivos, a partir da formulação de Marx, sem a devida contextualização do tempo presente e o reconhecimento das suas contradições, pode contribuir, no limite, para inviabilizar a unificação de lutas entre os próprios docentes e destes com o coletivo de trabalhadores. Isto porque pode dividir a categoria, dificultando a proposição de bandeiras de luta comuns tanto ao conjunto de

o fundamental não é qualificar se o trabalho é produtivo ou improdutivo, mas, sobretudo, identificar a relação social estabelecida, ou seja, onde se insere no circuito de produção e reprodução de valor. docentes do magistério superior, quanto ao coletivo de docentes da educação em todos os seus níveis, como ainda em relação aos trabalhadores contemporâneos que vivenciam fenômenos semelhantes de precarização e intensificação, em níveis avançados de exploração da força de trabalho. Portanto, é necessário unificar lutas e não cindi-las!

Para finalizar, podemos dizer que o essencial não são os rótulos de produtivo ou improdutivo na atualidade capitalista, mas sua localização efetiva no processo de exploração do trabalho e ampliação das formas de valorização do capital. Neste campo, a educação superior pública e seu conjunto de IES federais vêm assumindo um importante papel (seja nos serviços educacionais privados, nas pesquisas científicas voltadas para os interesses do mercado, bem como no desenvolvimento de novas tecnologias, ou mesmo na lógica do produtivismo acadêmico, etc.) na retomada dos níveis de acumulação do capital e na apropriação do trabalhado docente como parte do processo de valorização capitalista na atualidade.

Só a reflexão crítica sobre o momento atual, pautada em fundamentos teóricos sólidos (como o debate sobre trabalho produtivo e improdutivo na contemporaneidade), aliada a ações coletivas de resistência, podem vislumbrar novos caminhos para a universidade pública e o coletivo docente de graduação e pós-graduação em que o sentido e os rumos da educação possam transcender os limites do capital.

\section{Referências}

ANTUNES, R. A atualidade de Marx. Marília: UNESP, 2013. Palestra apresentada no V Seminário internacional teoria e prática do capitalismo. Disponível em: 〈http://youtu.be/YpJOSayJzdM〉. Acesso: 15 set. 2016.

BERTOLDO, E.; SANTOS, M. Trabalho docente e luta de classes. In: BERTOLDO, E.; MOREIRA, L. A. L.; JIMENEZ, S. (Orgs.). Trabalho, educação e formação humana frente à necessidade histórica da revolução. São Paulo: Instituto Lukács, 2012. p. 101-124. DAL ROSSO, S. Mais trabalho! A intensificação do labor na sociedade contemporânea. São Paulo: Boitempo, 2008.

DUARTE, J. L. N. Trabalho Docente do Assistente Social nas Federais: contradições e resistências em tempos de intensificação e produtivismo acadêmico. 2017. 467 f. Tese (Doutorado em Serviço Social) - Escola de Serviço Social, Universidade Federal do Rio de Janeiro, Rio de Janeiro, 2017. 
MANCEBO, D. Intensidade do trabalho docente: um debate necessário. In: CATANI, A. M.; SILVA JÚNIOR, J. R.; MENEGHEL, S. M. (Orgs.). A cultura da universidade pública brasileira: mercantilização do conhecimento e certificação em massa. São Paulo: Xamã, 2011. p. 29-40.

MARX, K. O Capital: crítica da economia política. Livro 1, vol. 1. São Paulo: Nova Cultural, 1985a. O Capital: crítica da economia política. Livro 1, vol. 2. São Paulo: Nova Cultural, 1985b.

Capítulo VI Inédito de O Capital. Resultados do Processo de Produção Imediata. São Paulo: Editora Moraes, 1985c.

. Teorias da mais-valia: história crítica do pensamento econômico. Vol. 1. (Livro 4 de O Capital). São Paulo: Civilização Brasileira, 1980.

SANTOS NETO, A. B. Trabalho produtivo e trabalho improdutivo nas “teorias da mais-valia” de Karl Marx. Em Debate, Florianópolis, n. 8, p. 5-22, jul./dez. 2012. Disponível em: <https://periodicos.ufsc.br/index.php/emdebate/article/view/1980-3532.2012n8p5/25510>. Acesso em: 07 ago. 2016.

SILVA JÚNIOR, J. R.; PIMENTA, A. V. Capitalismo, trabalho e educação: o caso das instituições federais de educação superior. Germinal, Salvador, v. 6, n. 2, p. 28-41, dez. 2014. Disponível em:

<http://www.portalseer.ufba.br/index.php/revistagerminal/article/viewFile/13086/9291>. Acesso em: 20 ago. 2016.

TEIXEIRA, F. J. S. Análise crítica do mercado de trabalho de Fortaleza à luz das categorias de Trabalho Produtivo e Improdutivo. Fortaleza: SINE/CE, 1988, p. 1-34.

Trabalho produtivo e improdutivo em Marx. Recife: CCSA/UFPE, 1999. p. 1-22.

\section{Notas}

1 É digno de nota afirmar que Marx se dedica às categorias trabalho produtivo e improdutivo em diversas passagens dos seus estudos, ficando evidente, conforme Teixeira (1999, p. 1) que "não existe uma sistematização nesta discussão, mesmo porque Marx não achou necessário fazer isso, já que para ele é um tipo de discussão que não requer muita preocupação, pelo menos dentro do sistema categorial de exposição de O capital". Contudo, Santos Neto (2012, p. 6) ressalta que um espaço privilegiado da obra marxiana que discute o tema, servindo de apoio para seus escritos mais elaborados em O capital, são os "Manuscritos de 1861-1863 que acabaram por se configurar nas 'Teorias da mais-valia: história crítica do pensamento econômico' (Capítulo IV de O capital)”. Neste trabalho, Marx (1985c) destaca sua posição relativa à natureza do trabalho produtivo e sua distinção com o trabalho improdutivo, tomando como ponto de partida os estudos de Adam Smith sobre o tema.

2 De acordo com Marx (1985a), inicialmente trabalhoé a transformação da natureza efetuada pelos seres humanos, a partir de meios e instrumentos, a fim de seguir um planejamento mental, ou melhor, uma antecipação ou um projeto que atenda objetivos humanos. No entanto, o homem, ao realizar uma transformação intencional da natureza, segundo seus interesses, também constrói e modifica a si próprio e às suas relações sociais. É este processo intencional que permite o salto qualitativo do homem como ser social.

3 Segundo Marx (1985a, p. 139), "por força de trabalho ou capacidade de trabalho entendemos o conjunto das faculdades físicas e espirituais que existem na corporalidade, na personalidade viva de um homem e que ele põe em movimento toda vez que produz valores de uso de qualquer espécie".

4 Santos Neto (2012, p. 9, grifos nossos) explica que "a definição adotada por Adam Smith de trabalho produtivo, como trabalho produtor de mercadorias, consiste numa expressão mais elementar do processo de produção de mercadorias do que a concepção de trabalho produtivo como trabalho que produz capital. Por sua vez, a noção do trabalho produtivo como trabalho que produz mercadorias serve para distingui-lo em relação aos mercantilistas e aos fisiocratas“, já que o próprio Marx (1980, p. 153) explica que "a definição da mais-valia dependia naturalmente da forma em que se concebia o próprio valor. Para o sistema monetário e para o mercantilista, o valor se representa em dinheiro; para os fisiocratas, em produto da terra, em produto agrícola; por fim, para A. Smith, em mercadoria pura e simples". Enquanto fisiocratas e mercantilistas debatiam sobre a oposição entre valor de uso (terra) e valor de troca (dinheiro), Smith avança no debate quando combina "as duas condições da mercadoria - valor de usoe valor de troca -, e assim é produtivo todo trabalho que se corporifica em qualquer valor de uso, em produto útil”, ou seja, que produza mercadoria. O que também significa dizer que a medida do valor desta mercadoriaé igual à determinada quantidade de tempo de trabalho social utilizado.

5 Marx (1985a, p. 176) esclarece a produção da mais-valia a partir da noção de trabalho excedente ou mais-trabalho: "o trabalhador labuta além dos limites do trabalho necessário, embora lhe custe trabalho, dispêndio de força de trabalho, não cria para ele nenhum valor. Ela gera a mais-valia, que sorri ao capitalista com todo o encanto de uma criação do nada. Essa parte da jornada de trabalho chamo de tempo de trabalho excedente, e o trabalho despendido nela: mais-trabalho (surplus labour). [...] essencial para a noção de mais-valia concebê-la como mero coágulo de tempo de trabalho excedente, como simples mais-trabalho objetivado".

6 Marx (1985b, p. 106) distingue ainda a mais-valia relativa e a absoluta: "o prolongamento da jornada de trabalho além do ponto em que o trabalhador teria produzido apenas um equivalente pelo valor de sua força de trabalho, e a apropriação desse mais-trabalho pelo capital - isso é a produção da mais-valia absoluta. Ela constitui a base geral do sistema capitalista e o ponto de partida para a produção da mais-valia relativa. Com esta, a jornada de trabalho está desde o princípio dividida em duas partes: trabalho necessário e mais-trabalho. A produção da mais-valia absoluta gira apenas em torno da duração da jornada de trabalho; a produção da mais-valia relativa revoluciona de alto a baixo os processos técnicos do trabalho e os agrupamentos sociais".

7 De acordo com o próprio Marx (1985b, p.188, nota n. 70): "Por 'proletário' só se deve entender economicamente o assalariado que produz e valoriza o capital eé jogado na rua assim que se torna supérfluo para as necessidades de valorização de 'Monsieur Capital', como Pecqueur chama a esse personagem". 
8 No âmbito das IES privadas este processo se evidencia, segundo os autores, a partir da observação da "expansão da indústria de serviços, especialmente a expansão orientada de forma direta pela racionalidade da predominância do capital financeiro na indústria da educação superior" (SILVA JÚNIOR; PIMENTA, 2014, p. 29), portando-se de maneira altamente rentável na sociedade dominada pelo capital financeiro.

9 Silva Jr. e Pimenta (2014, p. 36) revelam ainda que a tendência mundial sob o regime de predominância do "capital portador de juros apresenta muitos trabalhos improdutivos na sua aparência, porém, quando analisados nas suas articulações com outros trabalhos até o final da cadeia produtiva, sua maioria valoriza a produção ampliada do capital", podendo agregar valor ao capital.

10 “OPrograma Plataformas do Conhecimento, lançado por Dilma Rousseff em 25/07/2014, buscava a ampliação de R \$ 6 bilhões para R $\$ 24$ bilhões nos investimentos em pesquisa ligada ao aumento de produtividade, por meio da Financiadora de Projetos (FINEP). A tendência do programa em investir emáreas em que o país já tem experiências positivas, como agricultura, pecuária e aeronáutica, prenuncia a criação de uma rede de pesquisas que reúna empresas, setor público e institutos de pesquisas e se volte para investigação e desenvolvimento nas áreas selecionadas" (SILVA JÚNIOR; PIMENTA, 2014, p. 34).

\section{Janaína Lopes do Nascimento Duarte}

janaduarte@unb.br; jana.lopesduarte@gmail.com

Doutorado em Serviço Social pela Universidade Federal do Rio de Janeiro (UFRJ)

Professora do Departamento de Serviço Social da Universidade de Brasília (UnB)

\section{UnB}

Campus Universitário Darcy Ribeiro - Departamento de Serviço Social - SER - ICC Norte Brasília - Distrito Federal - Brasil

CEP: $70910-900$ 